Check for updates

Cite this: Mater. Chem. Front., 2020, 4, 1471

Received 2nd January 2020,

Accepted 1st March 2020

DOI: 10.1039/c9qm00792j

rsc.li/frontiers-materials

\title{
AlE-active Schiff base compounds as fluorescent probes for the highly sensitive and selective detection of $\mathrm{Fe}^{3+}$ ions $\uparrow$
}

\author{
Jonnagaddala Harathi (D) and Kathavarayan Thenmozhi (D) *
}

\begin{abstract}
Aggregation-induced emission (AIE)-active compounds are fascinating because of their unique property of restricted intramolecular rotation, and they can be exploited for manifold applications. Herein, we have designed and synthesized fluorescent salicylaldehyde derivatives, viz. 4-(tert-butyl)-2-((2-hydroxybenzylidene)amino)phenol (L1) and 4-(tert-butyl)-2-((2-hydroxy-5-methylbenzylidene)amino)phenol (L2), through facile Schiff base condensation. The photophysical properties of the as-synthesized ligands were investigated via UV-vis absorption and fluorescence emission spectral analysis. The ligands L1 and L2 acquired maximum AIE in THF : $\mathrm{H}_{2} \mathrm{O}$ (10\%: 90\%) and THF: $\mathrm{H}_{2} \mathrm{O}(40 \%: 60 \%)$, respectively, and showed exclusive AIE properties and high quantum yields $(\Phi)$ in the aggregated state. The fluorescence of the ligands $\mathbf{L} \mathbf{1}$ and $\mathbf{L} \mathbf{2}$ in the AIE state was selectively quenched by ferric $\left(\mathrm{Fe}^{3+}\right)$ ions. This fluorescence quenching is attributed to the inhibition of photoinduced electron transfer (PET) via complexation between the ligands and $\mathrm{Fe}^{3+}$ through ligand-to-metal charge transfer (LMCT). Job's plot revealed the formation of complexes between $\mathbf{L} \mathbf{1} / \mathbf{L} \mathbf{2}$ and $\mathrm{Fe}^{3+}$ in 1:1 stoichiometry. Further, the binding constants $\left(K_{\mathrm{a}}\right)$ were calculated using Benesi-Hildebrand plots and were found to be $1.31 \times 10^{5} \mathrm{M}^{-1}$ and $2.93 \times$ $10^{5} \mathrm{M}^{-1}$ for $\mathbf{L} 1$ and $\mathbf{L 2}$, respectively. The proposed mechanism of interaction has been defined using density functional theory (DFT) and also through electrochemical investigations using differential pulse voltammetry (DPV). Ligands L1 and L2 demonstrated very good and selective response towards the detection of $\mathrm{Fe}^{3+}$ ions; they exhibited detection limits of $0.163 \mu \mathrm{M}$ and $3.99 \mu \mathrm{M}$, respectively.
\end{abstract}

\section{Introduction}

Ferric ion $\left(\mathrm{Fe}^{3+}\right)$ plays an important role at the cellular level in several biochemical processes; both its deficiency and its surplus can result in several diseases, while iron storage and transport regulate metabolic processes. ${ }^{1} \mathrm{~A}$ higher amount of $\mathrm{Fe}^{3+}$ in the body has been associated with increased tendencies of certain cancers, abnormal functioning of organs such as the heart, pancreas and liver, and diseases such as anemia, Alzheimer's disease, epilepsy and hemochromatosis. ${ }^{2}$ The use of iron in day-to-day life and its crucial role in biological processes demands the development of techniques for monitoring $\mathrm{Fe}^{3+}$ in the environmental and biological fields. Therefore, the development of a sensor for the detection of $\mathrm{Fe}^{3+}$ with high selectivity and sensitivity is vastly desirable.

Several efforts have been made to detect $\mathrm{Fe}^{3+}$ ions using various analytical techniques, including electrochemical methods, inductively coupled plasma atomic emission spectroscopy and

Department of Chemistry, School of Advanced Sciences, Vellore Institute of Technology (VIT), Vellore-632014, India.E-mail: kt.thenmozhi@gmail.com, k.thenmozhi@vit.ac.in

$\dagger$ Electronic supplementary information (ESI) available: NMR, mass spectra, UV-visible and fluorescence spectral details of $\mathbf{L 1}$ and L2. See DOI: 10.1039/c9qm00792j atomic absorption spectrometry. ${ }^{3}$ These methods require sophisticated instrumentation, tedious sample preparation and trained manpower. Amongst these techniques, the colorimetric ${ }^{4}$ and fluorimetric ${ }^{5}$ methods are gaining increasing attention for the detection of significant metal ions, including $\mathrm{Fe}^{3+}$, due to their target ion-induced naked eye colour observations and changes in fluorescence. Fluorescence sensors offer inherent advantages in terms of response time, selectivity and sensitivity; thus, they are very attractive. ${ }^{6}$ Fluorescent molecular sensors are showing a wide range of development in various fields, including metal ion sensing, DNA sequencing and DNA fragmentation analysis, as well as in a variety of immunoassays. ${ }^{7}$

Based on the pioneering work on the aggregation-induced emission (AIE) effect, ${ }^{8}$ designing new molecules with AIE properties has recently garnered immense attention. ${ }^{9}$ AIE-active molecules exhibit either weak or no emission in solution, whereas their fluorescence intensity dramatically increases in the aggregated state. $^{10}$ In the AIE state, the intramolecular rotations are restricted through a variety of molecular interactions, including hydrogen bonding, $\pi-\pi$ interactions and steric effects; ${ }^{11}$ this results in the elimination of nonradiative transitions and the promotion of radiative transitions, affording strong emission. 
Owing to their interesting photophysical properties, these AIEactive molecules have found widespread applications in biosensors and optoelectronic devices as well as in the sensing of cations and anions. ${ }^{12} \mathrm{~A}$ few reports are available in the literature on the fluorescent sensing of metal ions, including $\mathrm{Fe}^{3+}$ ions. $^{13}$ However, there is still a need to design AIE-active fluorescent probes for the competent detection of $\mathrm{Fe}^{3+}$ because of the enormous importance of these ions in the arenas of biology, chemistry and the environment.

Schiff base compounds are regarded as pertinent candidates for fluorescent sensing because they exhibit higher fluorescence in organic solutions and AIE medium than in the solid state. ${ }^{14}$ Among the different probes explored, salicylaldehyde azomethines have exhibited exclusive properties. They undergo rapid $\mathrm{C}=\mathrm{N}$ isomerization in dilute solutions and are often non-fluorescent. This non-radiative process can be eliminated by the restriction of $\mathrm{C}=\mathrm{N}$ isomerization through hydrogen bonding in AIE medium, resulting in enhanced emission. ${ }^{15}$ Taking into account this rationale, we have synthesized luminescent AIE-active Schiff base compounds, viz. 4-(tert-butyl)-2-((2-hydroxybenzylidene)amino)phenol (L1) and 4-(tert-butyl)-2-((2-hydroxy-5-methyl-benzylidene)amino)phenol (L2), and investigated their photophysical properties. The efficacy of $\mathbf{L 1}$ and $\mathbf{L} 2$ towards metal ion sensing has been tested in $\mathrm{THF}$ and $\mathrm{THF}-\mathrm{H}_{2} \mathrm{O}$ media, and their fluorescence response has been examined through the photoinduced electron transfer (PET) mechanism. These ligands suffered from poor selectivity in THF, whereas both $\mathbf{L} 1$ and $\mathbf{L} 2$ demonstrated highly sensitive and selective response towards the colorimetric and fluorimetric detection of $\mathrm{Fe}^{3+}$ ion.

\section{Experimental}

\section{Materials}

Salicylaldehyde, 5-methylbenzaldehyde, 2-amino-4-tert-butylphenol and tetrabutylammonium perchlorate (TBAP) were purchased from Sigma-Aldrich, India, and the metal salts were obtained from Merck Chemicals, India. All the chemicals and solvents (AR grade) were utilized as received without any further purification. HPLC grade solvents and Milli-Q water were used for the preparation of stock solutions and dilutions during the photophysical investigations.

\section{Instrumentation and methods}

Nuclear magnetic resonance (NMR) spectra were recorded on a Bruker Avance $400 \mathrm{MHz}$ spectrometer (using TMS as the internal reference). Mass spectra were obtained using PerkinElmer (Clarus 680 GC and Clarus $600 \mathrm{MS}$ ) spectrometers. Infrared spectra (IR) were recorded using a Shimadzu FT-IR spectrometer (IR AffinityICE with resolution IV) within the range of 4000-400 $\mathrm{cm}^{-1}$. UV-vis absorption spectral analysis was performed using a Jasco spectrophotometer (UV-VIS-NIR-V-670) within the range of $200-800 \mathrm{~nm}$, and fluorescence emission spectra were recorded using a Hitachi (F-7000FL) fluorescence spectrophotometer within the range of 200-800 $\mathrm{nm}$. Lifetime measurements were performed using time correlation single photon counting (TCSPC). Electrochemical measurements were carried out using an electrochemical

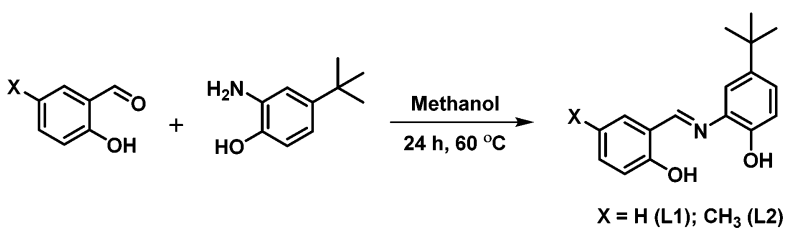

Fig. 1 Synthesis of the AIE-active ligands L1 and L2.

workstation (CHI 760E; CH instruments, USA) using a conventional three-electrode setup. Glassy carbon electrode, $\mathrm{Pt}$ wire and $\mathrm{Ag} / \mathrm{AgCl}$ (3 M KCl) were used as working, counter and reference electrodes, respectively. Stock solutions of $\mathbf{L} 1$ and $\mathbf{L} 2$ in $\mathrm{THF}$ with fixed concentrations of $1 \times 10^{-3} \mathrm{M}$ were prepared, and the solutions of metal salts were prepared in Milli-Q water. The test solutions for metal ion detection were prepared by diluting an appropriate aliquot of each metal ion and ligand stock solution. Solutions of $\mathbf{L 1}$ and $\mathbf{L} 2$ at $1 \times 10^{-5} \mathrm{M}$ concentrations in THF with different water fractions were prepared to analyze the AIE characteristics.

Synthesis of 4-(tert-butyl)-2-((2-hydroxybenzylidene)amino)phenol (L1). The ligand $\mathbf{L 1}$ was synthesized using a procedure reported earlier ${ }^{16}$ with slight modification, as shown in Fig. 1. 2-Hydroxybenzaldehyde ( $0.24 \mathrm{~g}, 2 \mathrm{mmol}$ ) was dissolved in $5 \mathrm{~mL}$ of methanolic solution and stirred, to which 2-amino-4-tert-butylphenol (0.33 g, $2 \mathrm{mmol}$ ) in methanol was added dropwise at room temperature. The reaction mixture was further refluxed at $60{ }^{\circ} \mathrm{C}$ for $24 \mathrm{~h}$. After cooling to room temperature, the excess solvent was removed and the ligand $\mathbf{L 1}$ was obtained as a dark orange solid. Yield: $85 \%$. ${ }^{1} \mathrm{H}$ NMR (400 MHz, DMSO- $d_{6}$ ): $\delta 1.29$ (s, 9H), 6.88-6.96 (p, 3H), 7.13-7.16 (q, 1H), 7.34-7.38 (t, 2H), 7.40-7.64 (t, 1H), $9.00(\mathrm{~s}, 1 \mathrm{H})$, $9.53(\mathrm{~s}, 1 \mathrm{H}), 13.91(\mathrm{~s}, 1 \mathrm{H}) \mathrm{ppm} .{ }^{13} \mathrm{C}$ NMR (100 MHz, DMSO- $\left.d_{6}\right): \delta$ $31.9,34.44,114.47,116.46,116.92,117.14,119.11,120.01$, 125.21, 132.79, 133.17, 134.96, 142.90, 149.15, 161.29, 162.01 ppm. IR (ATR) $\left(\nu \mathrm{cm}^{-1}\right): 2955(-\mathrm{OH}), 1613(\mathrm{C}=\mathrm{N}), 1476(\mathrm{C}=\mathrm{C})$, $1378(\mathrm{C}-\mathrm{N})$. GC-MS: $m / z$ calculated for $\left[\mathrm{M}^{+}\right]\left[\mathrm{C}_{17} \mathrm{H}_{19} \mathrm{NO}_{2}\right]^{+}$as 269.2416; found: 269.2438 .

Synthesis of 4-(tert-butyl)-2-((2-hydroxy-5-methylbenzylidene)amino)phenol (L2). The synthesis of $\mathbf{L 2}$ was carried out using a similar procedure to that followed for $\mathbf{L 1}$ by replacing 2-hydroxybenzaldehyde with 2-hydroxy-5-methylbenzaldehyde $(0.136 \mathrm{~g}$, $1 \mathrm{mmol}$ ) (Fig. 1). The product was obtained (yield: 90\%) as a red-brown solid. ${ }^{1} \mathrm{H}$ NMR (400 MHz, DMSO- $\left.d_{6}\right): \delta 1.26(\mathrm{~s}, 9 \mathrm{H})$, $2.25(\mathrm{~s}, 3 \mathrm{H}), 6.82(\mathrm{~d}, 2 \mathrm{H}), 7.1(\mathrm{~d}, 1 \mathrm{H}), 7.28(\mathrm{~d}, 1 \mathrm{H}), 7.41(\mathrm{~d}, 1 \mathrm{H})$, 8.91 (s, 1H), $9.46(\mathrm{~s}, 1 \mathrm{H}), 13.50(\mathrm{~s}, 1 \mathrm{H}) \mathrm{ppm} .{ }^{13} \mathrm{C} \mathrm{NMR}(100 \mathrm{MHz}$, DMSO- $\left.d_{6}\right): \delta 20.41,31.82,34.42,46.45,119.69,125.08,127.63$, 132.63, 133.91, 134.85, 142.50, 149.10, 158.97, 162.04 ppm. IR (ATR) $\left(\nu \mathrm{cm}^{-1}\right): 1600(\mathrm{C}=\mathrm{N}), 1571(\mathrm{C}-\mathrm{C}), 1486(\mathrm{C}=\mathrm{C}), 1273$ (C-N), $2927(-\mathrm{OH})$. GC-MS: $m / z$ calculated for $\left[\mathrm{M}^{+}\right]\left[\mathrm{C}_{18} \mathrm{H}_{21} \mathrm{NO}_{2}\right]^{+}$ as 283.2572 ; found: 283.2228 .

\section{Results and discussion}

The synthesized ligands, L1 and L2, were characterized using ${ }^{1} \mathrm{H}$ NMR, ${ }^{13} \mathrm{C}$ NMR, GC-MS and FT-IR spectra (Supplementary S1-S8, ESI $\dagger$ ), and the spectral data were in accordance with their structures. 

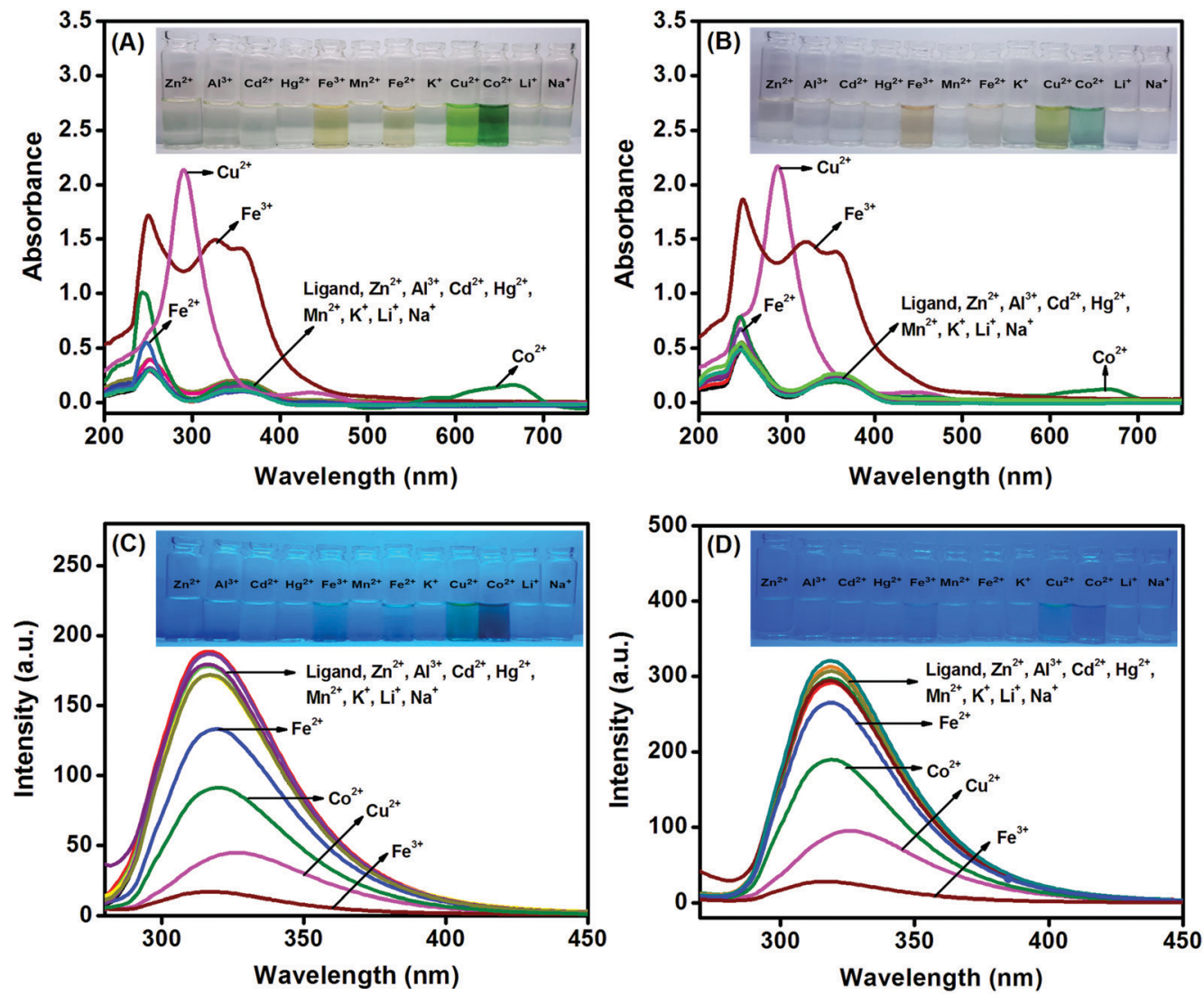

Fig. 2 Absorption spectra of $1 \times 10^{-5}$ M (A) L1 and (B) L2 in THF in the presence of 10 equivalents of various metal ions. Insets: Photographs of L1 and L2 with different metal ions in THF under a UV lamp at $254 \mathrm{~nm}$. Emission spectra of $1 \times 10^{-5} \mathrm{M}$ (C) L1 and (D) L2 in THF in the presence of different metal ions. Insets: Photographs of L1 and L2 with various metals under a UV lamp at $365 \mathrm{~nm}$.

\section{Photophysical properties and sensing behaviour in organic solvent}

The photophysical properties and sensing behaviour of the ligands $\mathbf{L 1}$ and L2 were investigated using UV absorption and fluorescence spectroscopy. First, the UV-vis spectra of the ligands $\mathbf{L 1}$ and $\mathbf{L} 2\left(1 \times 10^{-5} \mathrm{M}\right)$ were recorded in THF, and the spectra are shown in Fig. S9 (ESI $\dagger$ ). The molar absorptivity values were calculated for both the ligands, and the results are presented in Table S1 (ESI $\dagger$ ). L1 exhibited two absorbance peaks at 254 and $355 \mathrm{~nm}$ with molar absorptivities of $3.36 \times$ $10^{4} \mathrm{M}^{-1} \mathrm{~cm}^{-1}$ and $2.39 \times 10^{4} \mathrm{M}^{-1} \mathrm{~cm}^{-1}$, corresponding to the $\pi-\pi^{*}$ and $n-\pi^{*}$ transitions, respectively. Similarly, L2 exhibited two peaks at 256 and $356 \mathrm{~nm}$ with molar absorptivities of $2.97 \times 10^{4} \mathrm{M}^{-1} \mathrm{~cm}^{-1}$ and $1.99 \times 10^{4} \mathrm{M}^{-1} \mathrm{~cm}^{-1}$. Also, the fluorescence emission spectra of $\mathbf{L 1}$ and $\mathbf{L} 2$ were measured in THF $\left(1 \times 10^{-5} \mathrm{M}\right)$, and the emission peaks were observed at 317 and $320 \mathrm{~nm}$ for $\mathbf{L 1}$ and $\mathbf{L} 2$, respectively. Both the ligands exhibited excellent absorbance and emission characteristics; based on this, we decided to utilize these ligands towards colorimetric and fluorescent sensing. Because the ligands displayed better absorbance and fluorescence in THF medium (among the different solvents tested), THF was chosen as the solvent for further investigation.

The compounds $\mathbf{L} 1$ and $\mathbf{L} 2$ were designed with coordinating sites, such as imine nitrogen $(\mathrm{C}=\mathrm{N})$ and phenolic $(-\mathrm{OH})$ groups, which can effectively bind with metal ions and thus can be employed for metal ion detection. Initially, the colorimetric response of the ligands $\mathbf{L 1}$ and $\mathbf{L 2}$ towards various metal ions was tested by adding 10 equivalents of metal ions to $1 \times 10^{-5} \mathrm{M}$ of the ligand in THF. The interactions of different metal ions, such as $\mathrm{Al}^{3+}, \mathrm{Na}^{+}, \mathrm{Fe}^{3+}, \mathrm{Fe}^{2+}, \mathrm{Zn}^{2+}, \mathrm{Cu}^{2+}, \mathrm{Mn}^{2+}, \mathrm{Co}^{2+}, \mathrm{K}^{+}, \mathrm{Cd}^{2+}, \mathrm{Li}^{+}$ and $\mathrm{Hg}^{2+}$, with the ligands were tested in THF by naked eye observation under a UV lamp (inset: Fig. 2A-D). Ligands L1 and $\mathbf{L} 2$ were responsive towards $\mathrm{Fe}^{3+}, \mathrm{Cu}^{2+}$ and $\mathrm{Co}^{2+}$ ions and slightly responsive to $\mathrm{Fe}^{2+}$ ions. The solutions turned yellow upon the addition of $\mathrm{Fe}^{3+}$ and pale yellow upon the addition of $\mathrm{Fe}^{2+}$. Meanwhile, the solutions changed from colorless to green in the presence of $\mathrm{Cu}^{2+}$ and $\mathrm{Co}^{2+}$. Thus, the ligands $\mathbf{L} 1$ and $\mathbf{L} 2$ have demonstrated their potential to be developed as naked eye sensors.

In the next step, the interactions between the ligands and metal ions were probed by observing the changes in the absorbance and fluorescence intensities. Among the different metals tested with $\mathbf{L 1}$ and $\mathbf{L} 2$ in THF, $\mathrm{Co}^{2+}, \mathrm{Fe}^{2+}, \mathrm{Cu}^{2+}$ and $\mathrm{Fe}^{3+}$ ions showed noticeable absorbance responses at 254, 250, 300 and $650 \mathrm{~nm}$, respectively (Fig. 2A and B). In the fluorescence spectra (Fig. 2C and D), $\mathrm{Fe}^{3+}$ ions displayed prominent responses at 317 and $320 \mathrm{~nm}$ for $\mathbf{L 1}$ and $\mathbf{L 2}$, respectively, upon excitation at $255 \mathrm{~nm}$, whereas $\mathrm{Co}^{2+}$, $\mathrm{Fe}^{2+}$ and $\mathrm{Cu}^{2+}$ also showed reasonable responses. This clearly 
demonstrates that the selectivities of the probes $\mathbf{L 1}$ and $\mathbf{L} 2$ towards the detection of $\mathrm{Fe}^{3+}$ in THF medium are unsatisfactory, and we further intended to enhance the selectivity by suitably tuning the ligand-solvent system.

\section{Investigation of AIE characteristics}

According to literature reports, interference from other closely related transition metals can be overcome by using an AIE medium. $^{17}$

The ligands $\mathbf{L} 1$ and $\mathbf{L} 2$ are insoluble in water and highly soluble in organic solvents. The AIE behaviour of $\mathbf{L 1}$ and $\mathbf{L} 2$ were investigated in a solvent-non-solvent system $\left(\mathrm{THF}-\mathrm{H}_{2} \mathrm{O}\right)$ using different water fractions $\left(f_{\mathrm{w}} 0\right.$ to $\left.99.5 \%\right)$ (Fig. 3A and $\mathrm{B}$ ). The compounds $\mathbf{L} 1$ and $\mathbf{L} 2\left(1 \times 10^{-5} \mathrm{M}\right)$ showed weak fluorescence emissions in THF; meanwhile, the ligands were highly emissive in a THF- $\mathrm{H}_{2} \mathrm{O}$ mixture. The absorption spectra of ligands $\mathbf{L 1}$ and $\mathbf{L} 2$ were recorded in different water fractions from $10 \%$ to 99.5\% (Fig. S10A and B, ESI $\dagger$ ). The results revealed that the absorbance intensity gradually increased to a maximum at $90 \%$ and $60 \%$ water fractions for $\mathbf{L 1}$ and $\mathbf{L 2}$, respectively, in the UV region without any considerable change in its wavelength. Upon increasing $f_{\mathrm{w}}$ from $10 \%$ to $99.5 \%$, the fluorescence intensity (with an excitation wavelength of $255 \mathrm{~nm}$ ) gradually increased and reached a maximum at $90 \%$ water fraction for $\mathbf{L 1}$ at $317 \mathrm{~nm}$, and an emission maximum for $\mathbf{L} 2$ was attained with $60 \%$ at $320 \mathrm{~nm}$. The lower fluorescence intensities of $\mathbf{L 1}$ and $\mathbf{L} 2$ in THF medium is due to intramolecular $\mathrm{C}=\mathrm{N}$ isomerization. With increasing water content, the $\mathrm{C}=\mathrm{N}$ isomerization is gradually arrested through intramolecular hydrogen bonding. The elimination of nonradiative decay of the fluorescence during the formation of these aggregates results in the enhanced emission. When the $f_{\mathrm{w}}$ was increased beyond $90 \%$ for $\mathbf{L 1}$ and $60 \%$ for $\mathbf{L 2}$, the nanoaggregates of the salicylaldehyde azomethines underwent fast agglomeration and formed turbid solutions. The blue shift observed with this higher $f_{\mathrm{w}}$ may be due to scattering by the agglomerated particles in the turbid solution. With further increase in $f_{\mathrm{w}}$, the agglomeration would increase and the aggregates would precipitate out, resulting in a drastic decrease in the fluorescence intensity. The quantum yields $(\Phi)$ were calculated for both $\mathbf{L 1}$ and $\mathbf{L} 2\left(1 \times 10^{-5} \mathrm{M}\right)$ in THF-water mixtures with different ratios using anthracene in methanol $(\Phi=0.27)$ as a standard ref. 18 :

$$
\Phi_{\mathrm{s}}=\Phi_{\mathrm{r}} \frac{I_{\mathrm{s}} A_{\mathrm{s}} n_{\mathrm{s}}^{2}}{I_{\mathrm{r}} A_{\mathrm{r}} n_{\mathrm{r}}{ }^{2}}
$$

where $I_{\mathrm{r}}$ and $I_{\mathrm{S}}$ are the fluorescence intensities, $A_{\mathrm{r}}$ and $A_{\mathrm{s}}$ are the maximum absorbances, and $n_{\mathrm{s}}{ }^{2}$ and $n_{\mathrm{r}}{ }^{2}$ are the refractive indices of the sample and reference, respectively. As shown in Table S2 (ESI $\dagger$ ), the quantum yield values increased from 0.046 to 0.174 when the water fraction was increased from $0 \%$ to $90 \%$ for $\mathbf{L 1}$ and decreased to 0.149 with a $99.5 \%$ water fraction. Similarly, the $\Phi$ values for $\mathbf{L} 2$ increased from 0.017 to 0.136 upon increasing the water fraction from $0 \%$ to $60 \%$ and decreased to 0.035 with a $99.5 \%$ water fraction. The variation in the quantum yield values with different ratios of the THF-water mixture followed the same trend as the fluorescence intensity, demonstrating the AIE behaviour of $\mathbf{L 1}$ and $\mathbf{L 2}$ with 10\%: $90 \%$ and 40\%:60\% THF-water mixtures. Furthermore, we examined the morphologies of these nanoaggregates by recording SEM images of $\mathbf{L 1}$ and L2 in AIE medium (THF- $\mathrm{H}_{2} \mathrm{O}$ ). As observed in Fig. 3C and D,
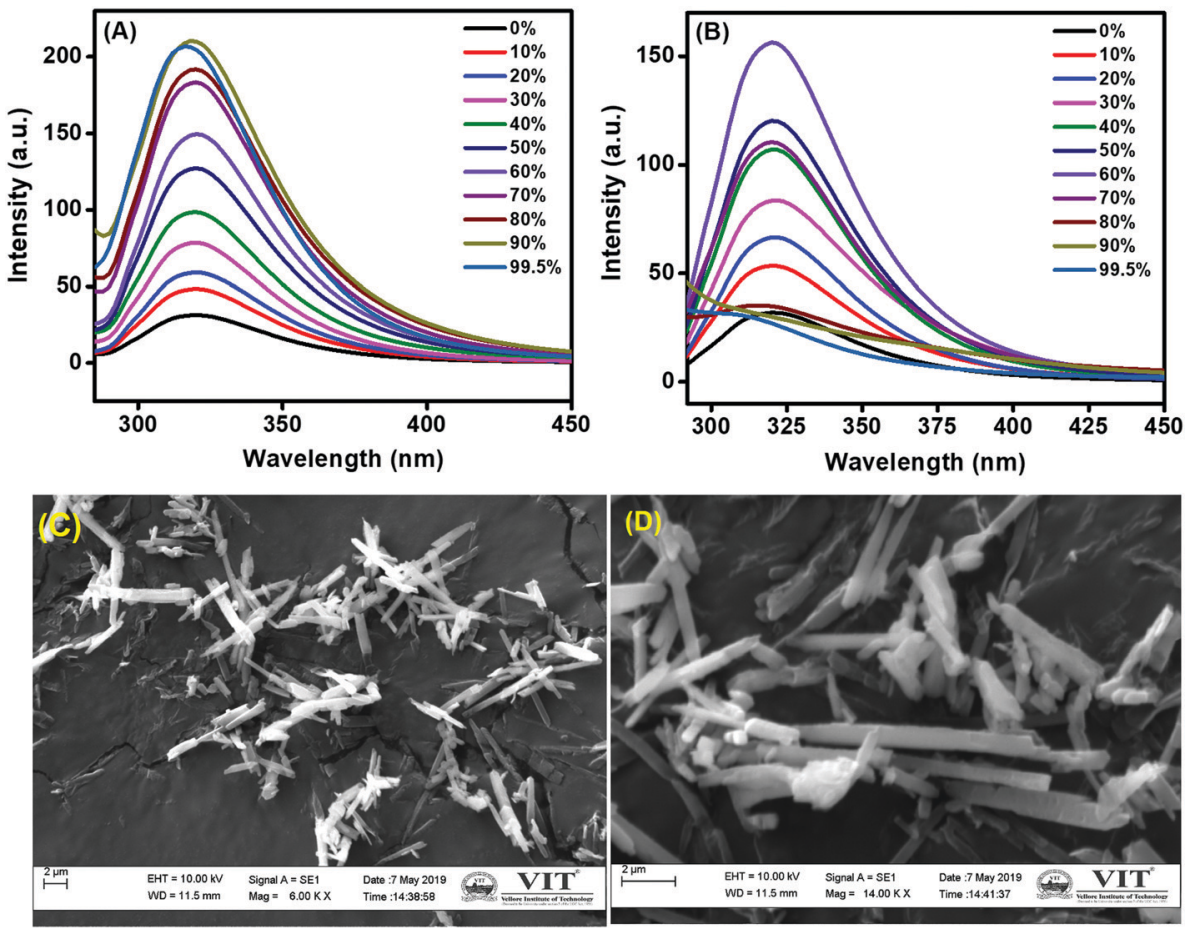

Fig. 3 Fluorescence spectra of $1 \times 10^{-5} \mathrm{M}(\mathrm{A}) \mathbf{L} \mathbf{1}$ and (B) $\mathbf{L} 2$ in THF- $\mathrm{H}_{2} \mathrm{O}$ with various water fractions. SEM images of (C) $\mathbf{L} 1\left(10 \%: 90 \%\right.$, THF : $\left.\mathrm{H}_{2} \mathrm{O}\right)$ and (D) $\mathbf{L} 2$ (40\%: $60 \%$, THF : $\left.\mathrm{H}_{2} \mathrm{O}\right)$. 

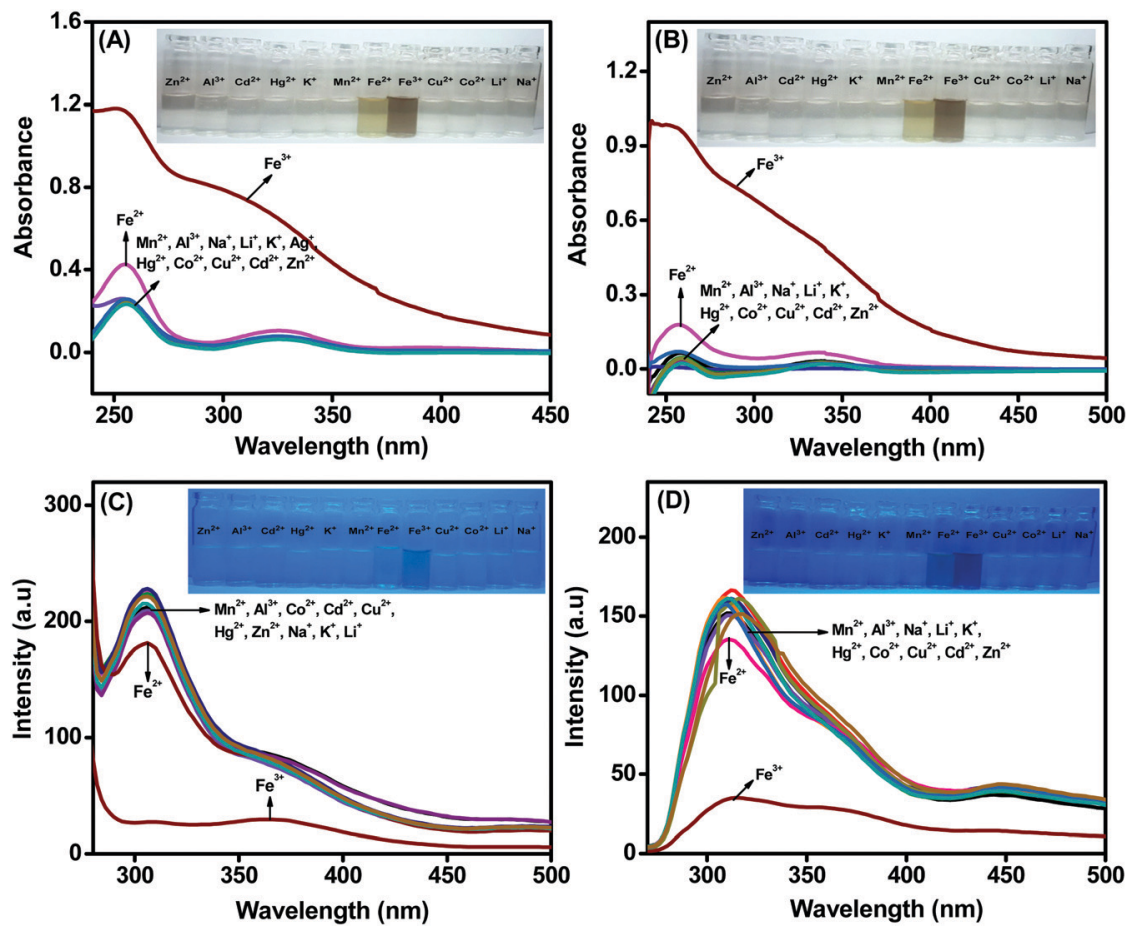

Fig. 4 Absorption spectra of (A) L1 and (B) L2 in the presence of different metal ions in THF : $\mathrm{H}_{2} \mathrm{O}$ with $10: 90 \%$ (L1) and $40: 60 \%$ (L2) mixtures. Insets: Photographs of $\mathbf{L} 1$ and $\mathbf{L} 2$ in the presence of different metal ions in THF: $\mathrm{H}_{2} \mathrm{O}$ fractions under a UV lamp at $254 \mathrm{~nm}$. Fluorescence spectra of (C) $\mathbf{L} \mathbf{1}$ and (D) L2 with different metal ions in THF: $\mathrm{H}_{2} \mathrm{O}$. Insets: Photographs of $\mathbf{L} \mathbf{1}$ and $\mathbf{L} 2$ in the presence of various metals in AIE medium under a UV lamp at $365 \mathrm{~nm}$

both ligands in $\mathrm{THF}-\mathrm{H}_{2} \mathrm{O}(10 \%: 90 \%$ and $40 \%: 60 \%)$ mixtures showed crystalline morphologies and formation of nanoaggregates, which resulted in the enhanced emissions. ${ }^{19}$ Thus, it is clear that both $\mathbf{L} 1$ and $\mathbf{L} 2$ exhibit remarkable aggregation properties; therefore, they are suitable to be explored as AIE-active fluorescent probes for the selective detection of $\mathrm{Fe}^{3+}$ ion.

\section{Selective binding of $\mathrm{Fe}^{3+}$ in AIE medium}

Achieving good selectivity towards $\mathrm{Fe}^{3+}$ ions over dissimilar concomitant ions is essential to evaluate the competence of a sensor for practical applications. The abilities of the ligands $\mathbf{L 1}$ and $\mathbf{L} \mathbf{2}$ to selectively bind $\mathrm{Fe}^{3+}$ were evaluated by monitoring the variation in fluorescence intensity with continual addition of different metal ions. Experiments were performed at optimized conditions of $\mathrm{THF}-\mathrm{H}_{2} \mathrm{O}$ mixtures of $10: 90$ and $40: 60$ volume \% in the presence of $1 \times 10^{-5} \mathrm{M}$ concentrations of ligands $\mathbf{L 1}$ and L2, respectively. The absorbance (Fig. 4A and B) and fluorescence (Fig. 4C and D) spectral investigations indicate that $\mathbf{L 1}$ and $\mathbf{L 2}$ demonstrate very good selectivity towards $\mathrm{Fe}^{3+}$ ions among various metal ions, such as $\mathrm{Al}^{3+}, \mathrm{Fe}^{2+}, \mathrm{Na}^{+}, \mathrm{Mn}^{2+}, \mathrm{Zn}^{2+}, \mathrm{Cd}^{2+}$, $\mathrm{Cu}^{2+}, \mathrm{Co}^{2+}, \mathrm{Hg}^{2+}, \mathrm{Li}^{+}$, and $\mathrm{K}^{+}$, in $\mathrm{THF}-\mathrm{H}_{2} \mathrm{O}$. No significant change in the absorption and emission spectra was noted with either ligand, even upon addition of 10 equivalents of various metal ions, except $\mathrm{Fe}^{3+}$. Slight or negligible interference was observed with $\mathrm{Fe}^{2+}$ ions for both the ligands. The pictorial representation of the response of ligands $\mathbf{L} \mathbf{1}$ and $\mathbf{L} \mathbf{2}$ towards different metal ions under UV light (inset: Fig. 4A and B) illustrate the selectivity of the ligand towards $\mathrm{Fe}^{3+}$ ions. Further, the results shown in the inset to Fig. 4C and D indicate that both compounds can be utilized for the selective detection of $\mathrm{Fe}^{3+}$ ions with maximum turn-off fluorescence intensities.

Both the ligands exhibited fluorescence quenching towards four metal ions $\left(\mathrm{Co}^{2+}, \mathrm{Fe}^{2+}, \mathrm{Cu}^{2+}\right.$ and $\left.\mathrm{Fe}^{3+}\right)$ in THF medium, whereas selective quenching towards $\mathrm{Fe}^{3+}$ ions was observed in the AIE medium. In pure THF medium, the acidic protons of $\mathrm{Ar}-\mathrm{OH}$ in $\mathbf{L 1} / \mathbf{L} 2$ will be less labile; thus, the $\mathrm{Ar}-\mathrm{OH}$ and $\mathrm{C}=\mathrm{N}$ groups may provide soft base binding sites. In the presence of water along with THF in the AIE medium, the phenolic protons could be deprotonated to form phenoxide ion $\left(\mathrm{Ar}-\mathrm{O}^{-}\right)$, thus providing a hard base binding site. ${ }^{20}$ Metals such as $\mathrm{Co}^{2+}, \mathrm{Fe}^{2+}$ and $\mathrm{Cu}^{2+}$ ions are borderline acids and will have reasonable affinity with the ligands in THF medium (due to the soft base binding sites) and poor affinity with the ligands in the THFwater mixture (due to the hard base binding sites). On the other hand, $\mathrm{Fe}^{3+}$ ion, as a hard acid, will have higher affinity towards phenoxide ion in the THF-water mixture than the borderline acids; thus, the ligands $\mathbf{L 1}$ and $\mathbf{L 2}$ both demonstrate high selectivity towards $\mathrm{Fe}^{3+}$ ion in AIE medium.

The selectivity of the ligands in THF- $\mathrm{H}_{2} \mathrm{O}$ mixture was also tested by recording the fluorescence spectra in the presence of $1 \times 10^{-5} \mathrm{M}$ ligand containing 10 equivalents of $\mathrm{Fe}^{3+}$, to which equal concentrations of other metal ions were added (Fig. S11, ESI $\dagger$ ). The black bars show that upon interaction with $\mathrm{Fe}^{3+}$, both $\mathbf{L 1}$ and $\mathbf{L} 2$ afforded significant changes in their fluorescence emission intensities. It could be observed that the tested metal ions present in equal amounts did not influence the fluorescence 

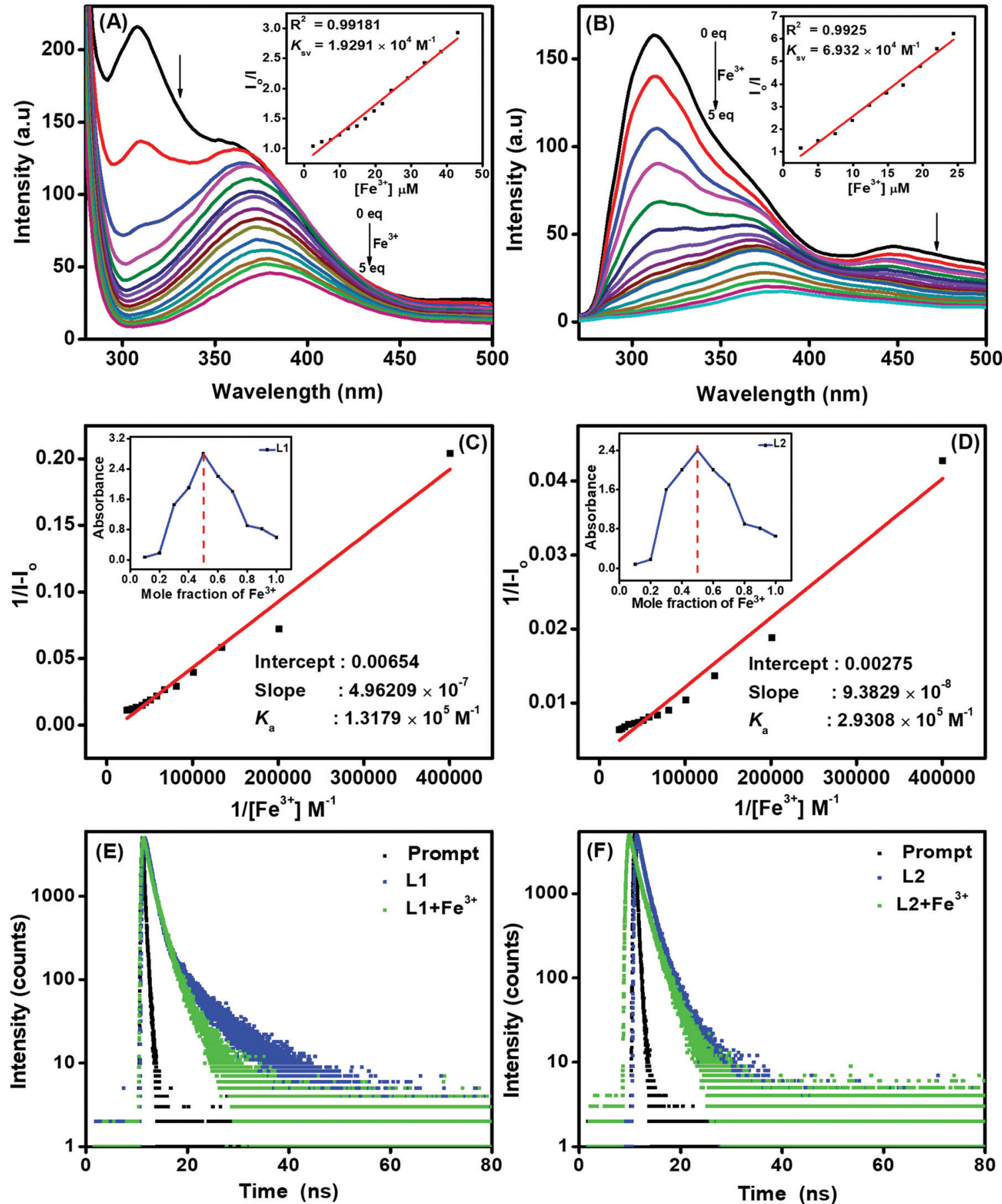

Fig. 5 Fluorescence titration spectra with $1 \times 10^{-5} \mathrm{M}(\mathrm{A}) \mathbf{L} 1$ and $\mathbf{L} 2(\mathrm{~B})$ in $\mathrm{THF}-\mathrm{H}_{2} \mathrm{O}(10 \%: 90 \%$ and $40 \%: 60 \%)$ upon successive addition of Fe $\mathrm{e}^{3+}$ ions $(0$ to 5 equivalents) $\left(\lambda_{\mathrm{ex}}=255 \mathrm{~nm}\right.$ ). Insets: $K_{\mathrm{sv}}$ plots for $\mathbf{L} \mathbf{1}$ and $\mathbf{L} \mathbf{2}$. B-H plots of (C) L1 and (D) L2 using 1: 1 stoichiometry for the associations of $\mathbf{L} \mathbf{1}$ and $\mathbf{L} \mathbf{2}$ with $\mathrm{Fe}^{3+}$ ions. Insets: Job's plot for the complexation of $\mathbf{L} 1$ and $\mathbf{L} 2$ with $\mathrm{Fe}^{3+}$ ions plotted using absorbance changes by the mole fraction method. Fluorescence lifetime decay plots of $\mathrm{L} 1(\mathrm{E})$ and $\mathbf{L} 2(\mathrm{~F})$ in the absence and presence of $\mathrm{Fe}^{3+}$ ion.

quenching caused by $\mathrm{Fe}^{3+}$. This confirms that remarkable selectivity towards $\mathrm{Fe}^{3+}$ ions (in the presence of different metal ions) can be attained with both the ligands in AIE medium.

\section{Detection of $\mathrm{Fe}^{3+}$ using $\mathrm{L} 1$ and $\mathrm{L} 2$ in $\mathrm{THF}-\mathrm{H}_{2} \mathrm{O}$}

To expand the scope of the AIE-active probes as suitable candidates for quantitative sensing of $\mathrm{Fe}^{3+}$ ions, the absorption and fluorescence spectra of $\mathbf{L} \mathbf{1}$ and $\mathbf{L} \mathbf{2}$ were examined in the presence of increasing concentrations of $\mathrm{Fe}^{3+}$ ions. The absorption spectra of $\mathbf{L} \mathbf{1}$ and $\mathbf{L} 2$ in the presence of different concentrations of $\mathrm{Fe}^{3+}$ ions are presented in Fig. S12(A) and (B) (ESI $\dagger$ ). The absorption spectra of both $\mathbf{L} 1$ and $\mathbf{L} 2$ show increases in peak intensity upon the gradual addition of $\mathrm{Fe}^{3+}$ ions in $\mathrm{THF}-\mathrm{H}_{2} \mathrm{O}$ (10\%:90\% and $40 \%: 60 \%)$ at 255 and $355 \mathrm{~nm}$, respectively. 
Table 1 Lifetime and quantum yield parameters of $\mathbf{L} \mathbf{1}$ and $\mathbf{L} \mathbf{2}$ in THF : $\mathrm{H}_{2} \mathrm{O}$ $(10 \%: 90 \%$ and $40 \%: 60 \%)$ in the presence and absence of $\mathrm{Fe}^{3+}$

\begin{tabular}{lllll}
\hline Sample & $\tau_{\text {avg }}$ & $\Phi$ & $K_{\mathrm{r}}\left(\mathrm{ns}^{-1}\right)$ & $K_{\mathrm{nr}}\left(\mathrm{ns}^{-1}\right)$ \\
\hline $\mathbf{L 1}$ & 6.98 & 0.174 & 0.024 & 0.118 \\
$\mathbf{L 1}+\mathrm{Fe}^{3+}$ & 3.49 & 0.013 & 0.0037 & 0.282 \\
$\mathbf{L 2}$ & 4.86 & 0.136 & 0.027 & 0.177 \\
$\mathbf{L 2}+\mathrm{Fe}^{3+}$ & 2.5 & 0.01 & 0.004 & 0.396
\end{tabular}

In addition, to investigate the efficiency of $\mathbf{L 1}$ and $\mathbf{L} 2$ towards $\mathrm{Fe}^{3+}$ recognition, we performed fluorescence titration in THF$\mathrm{H}_{2} \mathrm{O}$ medium at an excitation wavelength of $255 \mathrm{~nm}$. As shown in Fig. 5A and B, a gradual decrease in the fluorescence intensities of $\mathbf{L} 1$ at 317 and $355 \mathrm{~nm}$ as well as at 320 and $450 \mathrm{~nm}$ for $\mathbf{L} 2$ was observed upon successive addition of $\mathrm{Fe}^{3+}$ ion. The fluorescence quenching behaviour of $\mathbf{L 1}$ and $\mathbf{L} 2$ in the presence of $\mathrm{Fe}^{3+}$ confirms the formation of a ligand-to-metal charge transfer (LMCT) complex due to the photoinduced electron transfer (PET) process.

In order to interpret the fluorescence quenching behaviour of the ligands in the presence of $\mathrm{Fe}^{3+}$ ions, the quenching efficiency was calculated using the Stern-Volmer equation $I_{0} / I=1+K_{\mathrm{sv}}[Q]^{21}$ (where $I_{0}$ is the initial fluorescence intensity of the ligand in the absence of $\mathrm{Fe}^{3+}, I$ is the fluorescence intensity in the presence of $\mathrm{Fe}^{3+}$ and $Q$ is the quenching constant). The plot of $I_{0} / I$ against the concentration of $\mathrm{Fe}^{3+}$ was found to be linear, and the Stern-Volmer constants $\left(K_{\mathrm{sv}}\right)$ were estimated to be $1.929 \times 10^{4} \mathrm{M}^{-1}$ and $6.932 \times$ $10^{4} \mathrm{M}^{-1}$ for $\mathbf{L 1}$ and $\mathbf{L} 2$, respectively. The S-V plots suggest that fluorescence involves a static quenching process, and the obtained $K_{\mathrm{Sv}}$ values were found to be comparable to or better than those of previously reported $\mathrm{Fe}^{3+}$ sensors. ${ }^{22}$

Further, the binding affinities were estimated using the Benesi-Hildebrand (B-H) plot of $1 /\left[I-I_{0}\right]$ vs. $1 /\left[\mathrm{Fe}^{3+}\right]$. The $\mathrm{B}-\mathrm{H}$ plots for the titration of the ligands with $\mathrm{Fe}^{3+}$ ions resulted in linear relationships, and the association constants $\left(K_{\mathrm{a}}\right)$ of the probes L1 and L2 (Fig. 5C and D) were calculated to be $1.317 \times$ $10^{5} \mathrm{M}^{-1}$ and $2.930 \times 10^{5} \mathrm{M}^{-1}$, respectively. The higher association constants (Table 2) confirm the strong binding affinities of both the ligands for complexation with $\mathrm{Fe}^{3+}$, resulting in sensitive detection of the same. In order to probe the reason for the selectivity of our ligands towards $\mathrm{Fe}^{3+}$ ion in AIE medium, we calculated $K_{\mathrm{a}}$ for $\mathrm{Fe}^{2+}$, $\mathrm{Fe}^{3+}, \mathrm{Co}^{2+}$ and $\mathrm{Cu}^{2+}$ metals in THF and AIE medium (Table S3, ESI $\dagger$ ). All the metal ions showed very similar binding constants in THF medium. However, the $K_{\mathrm{a}}$ of $\mathrm{Fe}^{3+}$ with $\mathbf{L 1} / \mathbf{L} 2$ was very high ( $\sim 10$ to 30 times) compared to those of $\mathrm{Fe}^{2+}, \mathrm{Co}^{2+}$ and
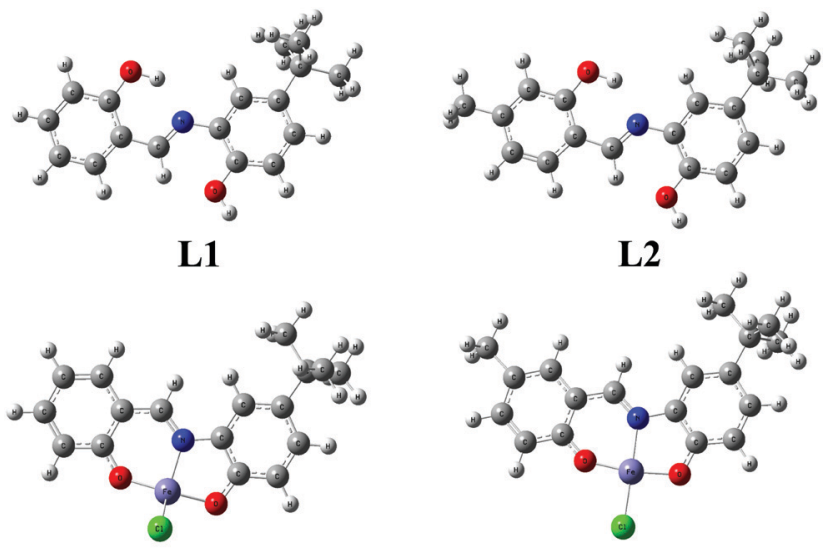

$\mathbf{L 1}-\mathrm{Fe}^{3+}$

$\mathbf{L} 2-\mathrm{Fe}^{3+}$

Fig. 6 DFT optimized structures of L1, L2, $\mathbf{L} 1-\mathrm{Fe}^{3+}$ and $\mathbf{L} 2-\mathrm{Fe}^{3+}$

$\mathrm{Cu}^{2+}$ in AIE medium. This observation demonstrates that the ligands $\mathbf{L 1} / \mathbf{L} 2$ exhibit higher binding affinity towards $\mathrm{Fe}^{3+}$ in AIE medium than the other metals investigated, which affords higher selectivity.

To determine the binding sites and ligand-metal stoichiometry, the continuous variation (Job's plot) methodology was used by plotting the changes in absorption maximum as a function of mole fraction at 255 and $256 \mathrm{~nm}$ for $\mathbf{L 1}$ and L2, respectively. During UV-visible absorption titrations, the plot exhibited maximum absorbance when the mole fraction of $\mathrm{Fe}^{3+}$ reached 0.5; thus, the stoichiometries of both $\mathbf{L} 1$ and $\mathbf{L} 2$ towards $\mathrm{Fe}^{3+}$ complex were established to be 1:1 (insets to Fig. 5C and D). From the fluorescence titrations, the detection limits of sensors $\mathbf{L 1}$ and $\mathbf{L} 2$ for $\mathrm{Fe}^{3+}$ ions were calculated to be 0.163 and $3.99 \mu \mathrm{M}$, respectively, using the equation $3 \sigma / S$, where $\sigma$ denotes the standard deviation of blank measurements and $S$ is the slope obtained for the plot of intensity $v s$. $\mathrm{Fe}^{3+}$ ion concentration. As shown in Table 2, sensors $\mathbf{L 1}$ and $\mathbf{L 2}$ both exhibit promising analytical characteristics in terms of high selectivity, high binding efficiency and low detection limit towards the quantitative detection of $\mathrm{Fe}^{3+}$ ion.

\section{Quantum yield and lifetime measurements}

The sensing behaviour of the probes $\mathbf{L 1}$ and $\mathbf{L} 2$ towards the detection of $\mathrm{Fe}^{3+}$ was also examined with quantum yield and lifetime measurements. The fluorescence decay behaviour of $\mathbf{L 1}$ and $\mathbf{L} 2$ in the presence and absence of $\mathrm{Fe}^{3+}$ ions was assessed using time-resolved spectrofluorometry, and the results are

Table 2 Comparison of $\mathbf{L} 1$ and $\mathbf{L} 2$ with recently reported fluorescent $\mathrm{Fe}^{3+}$ sensors

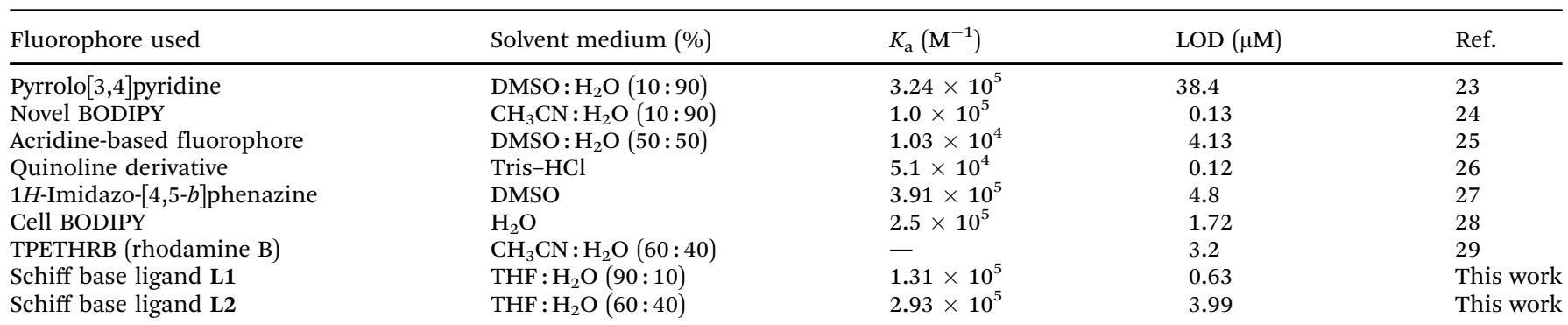


given in Fig. 5E and F. The average fluorescence lifetimes of $\mathbf{L 1}$ and $\mathrm{L} 2$ in $\mathrm{THF}-\mathrm{H}_{2} \mathrm{O}$ were found to be 6.98 and $4.86 \mathrm{~ns}$, respectively. However, shorter fluorescence lifetimes of 3.49 and 2.5 ns were observed for $\mathbf{L} 1$ and $\mathbf{L} 2$, respectively, in the presence of $\mathrm{Fe}^{3+}$ ions. We also estimated the radiative $\left(k_{\mathrm{r}}\right)$ and nonradiative $\left(k_{\mathrm{nr}}\right)$ decay values of both $\mathbf{L 1}$ and $\mathbf{L 2}$ in the presence of $\mathrm{Fe}^{3+}$, and the values are summarized in Table 1. The calculated $k_{\mathrm{r}}$ and $K_{\mathrm{nr}}$ values of both $\mathbf{L 1}$ and $\mathbf{L} 2$ with $\mathrm{Fe}^{3+}$ show a decrease in $k_{\mathrm{r}}$ decay and an increase in $K_{\mathrm{nr}}$ decay. This reasonable reduction of radiative processes and enhancement of nonradiative processes results in fluorescence quenching of $\mathbf{L} \mathbf{1}$ and $\mathbf{L} 2$ in the presence of $\mathrm{Fe}^{3+}$ ions.

Further, the quantum yield values were calculated in the presence and absence of $\mathrm{Fe}^{3+}$ in THF : $\mathrm{H}_{2} \mathrm{O}(10 \%: 90 \%$ for $\mathbf{L 1}$ and $40 \%: 60 \%$ for $\mathbf{L} 2$ ). The quantum yields of $\mathbf{L} 1$ and $\mathbf{L} 2$ in the absence of $\mathrm{Fe}^{3+}$ were found to be 0.174 and 0.136 , which decreased

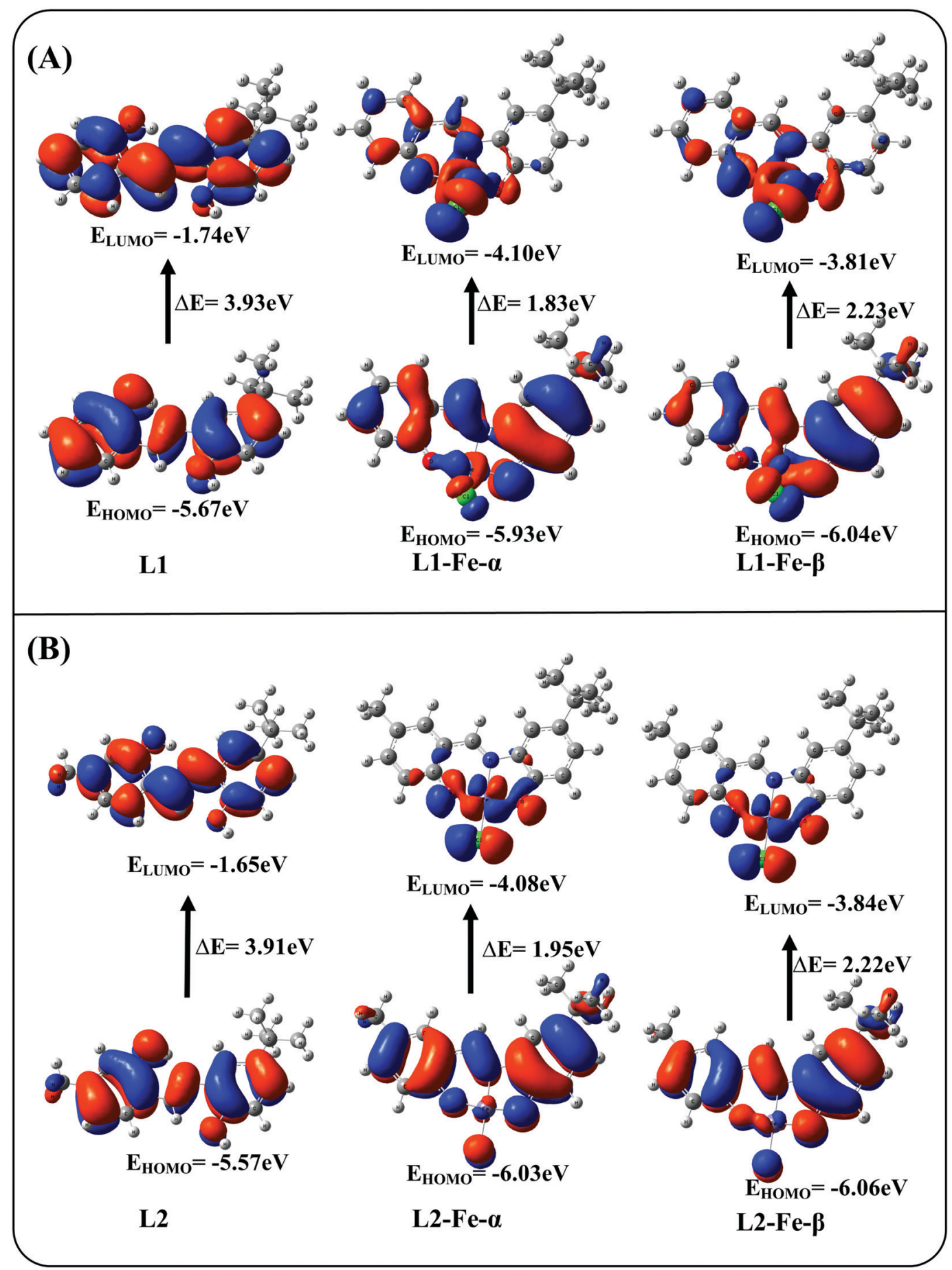

Fig. 7 Frontier molecular orbitals of (A) L1 and (B) L2 and their Fe ${ }^{3+}$ complexes calculated using the DFT/B3LYP method. 
to 0.013 and 0.01 , respectively, in the presence of $\mathrm{Fe}^{3+}$ ions. The drastic drop in the quantum yield values during the ligand- $\mathrm{Fe}^{3+}$ complexation ensures that the interactions of $\mathbf{L 1}$ and $\mathbf{L} 2$ with $\mathrm{Fe}^{3+}$ in the excited state lead to fluorescence quenching.

\section{Theoretical studies}

To gain better insight into the binding mechanisms of L1 and L2 with $\mathrm{Fe}^{3+}$ ion, density functional theory (DFT) calculations were performed using the Gaussian 09W program in the gas phase. The spatial distributions as well as the electron distributions in the molecular orbitals of the ligands and ligand- $\mathrm{Fe}^{3+}$ complexes were also explored using DFT. The basis set at 6-31G** was used for the $\mathrm{N}, \mathrm{O}, \mathrm{C}, \mathrm{H}$, and $\mathrm{Cl}$ atoms of $\mathbf{L 1}$ and $\mathbf{L 2}$, whereas LANL2DZ was utilized for $\mathrm{Fe}^{3+}$ atom. The optimized geometries of L1, L2, L1- $\mathrm{Fe}^{3+}$ and $\mathbf{L 2}-\mathrm{Fe}^{3+}$ are shown in Fig. 6. The interaction energy $\left(E_{\text {int }}=E_{\text {complex }}-E_{\mathrm{L}}\right)$ of $\mathbf{L 1}-\mathrm{Fe}^{3+}$ was found to be 1140.129 , and $1140.177 \mathrm{kcal} \mathrm{mol}^{-1}$ was found for $\mathbf{L} 2-\mathrm{Fe}^{3+}$. The obtained bond lengths of $\mathrm{N}-\mathrm{Fe}^{3+}, \mathrm{O}_{1}-\mathrm{Fe}^{3+}$ and $\mathrm{O}_{2}-\mathrm{Fe}^{3+}$ of the $\mathbf{L 1}$ and $\mathbf{L} 2$ complexes were 1.9116, 1.7938 and $1.8397 \AA$ and 1.9971, 1.7628 and $1.8158 \AA$, respectively.

The electron distributions of the $\mathbf{L 1} / \mathbf{L} 2-\mathrm{Fe}^{3+}$ complexes were investigated on the basis of frontier molecular orbitals (FMO), and their structures are shown in Fig. 7A and B. In the cases of $\mathbf{L 1}$ and L2, the highest occupied molecular orbitals (HOMO) and lowest unoccupied molecular orbitals (LUMO) are fully located over the molecules, with band gaps of 3.93 and $3.91 \mathrm{eV}$, respectively; this facilitates $\pi-\pi^{*}$ electron transfer from the $\mathbf{L} 1$ and $\mathbf{L} 2$ molecules. In the case of ligands with $\mathrm{Fe}^{3+}$ complexation, the electron clouds of the ligands spread from the ligands to the metal, and the LMCT is due to the unpaired electrons present in the FMO. The unpaired electrons of the FMO further split into $\alpha$-FMO and $\beta$-FMO. The $\alpha, \beta$-HOMO and LUMO orbitals of $\mathbf{L 1}-\mathrm{Fe}^{3+}$ and $\mathbf{L} 2-\mathrm{Fe}^{3+}$ are located on the ligands as well as on the metal complexes, with band gaps of 1.83 and $2.23 \mathrm{eV}$ for $\alpha$-FMO and 1.95 and $2.22 \mathrm{eV}$ for $\beta$-FMO, respectively. These results confirm the excited state $\pi-\pi^{*}$ transitions, which result in fluorescence emission quenching. The energy gaps of $\mathbf{L 1}$ and $\mathbf{L} 2$ increased and the energy band gaps of the ligand$\mathrm{Fe}^{3+}$ complexes decreased for both the ligands. This band gap analysis reveals the stabilization of the complex due to the lowering of energy and the strong complexation occurring in $\mathbf{L} 1-\mathrm{Fe}^{3+}$ and $\mathbf{L} 2-\mathrm{Fe}^{3+}$. The formation of the 1:1 LMCT complex ratio confirms the $1: 1$ stoichiometry, which is supplemented well with the Job plot experimental results of the fluorophores L1 and L2; this further corroborates the PET process.

\section{Electrochemical investigation of the ligand- $\mathrm{Fe}^{3+}$ interactions}

The interactions of ligands $\mathbf{L} 1$ and $\mathbf{L} 2$ with $\mathrm{Fe}^{3+}$ ion were further explored by differential pulse voltammetry (DPV). The DPVs of 1 $\mathrm{mM} \mathbf{L} 1$ and $\mathbf{L 2}$ in the absence and presence of incremental concentrations of $\mathrm{Fe}^{3+}$ were recorded in $\mathrm{CH}_{3} \mathrm{OH}$ with $0.1 \mathrm{M}$ TBAP as the supporting electrolyte at a scan rate of $50 \mathrm{mV} \mathrm{s}^{-1}$ (Fig. 8A and B). The voltammograms of $\mathbf{L 1}$ and $\mathbf{L} 2$ show two sets of well-defined oxidation peaks. The oxidation peaks for ligand L1 occurred at 0.78 and $1.01 \mathrm{~V}$ and those of $\mathbf{L} 2$ occurred at 0.79 and $1.15 \mathrm{~V}$. The similar oxidation potentials of the first peaks
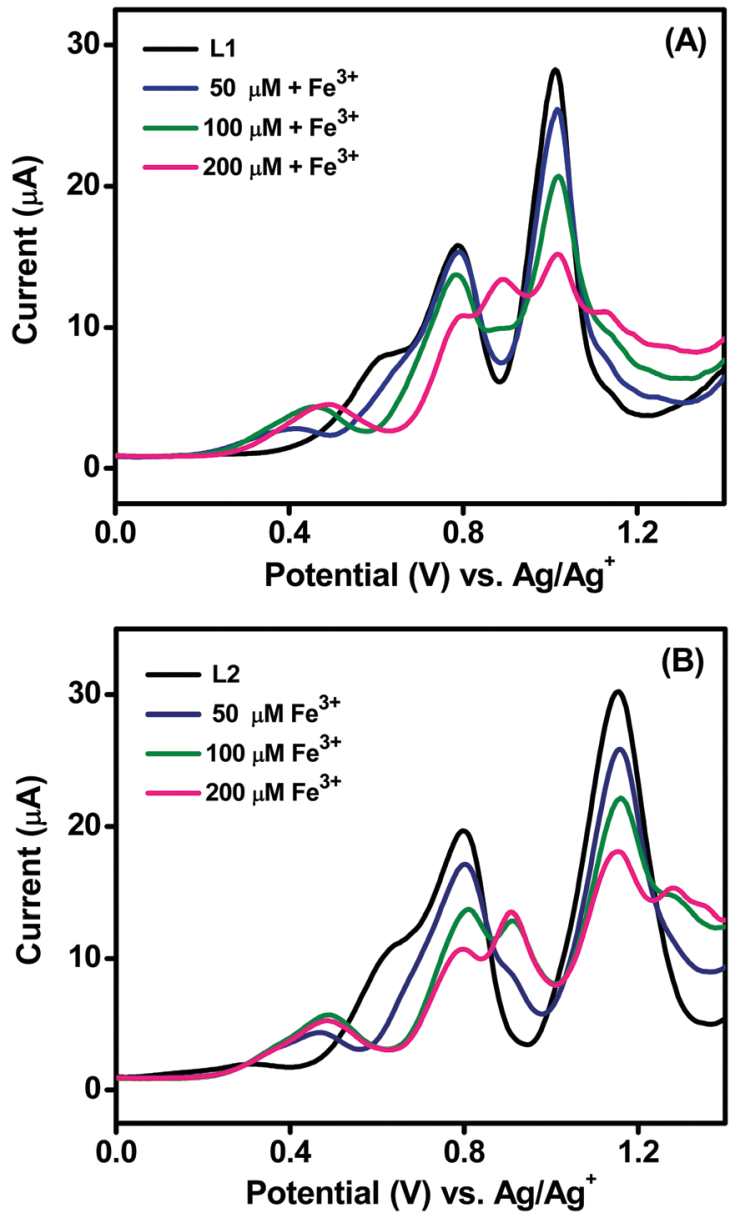

Fig. 8 DPVs of $1 \mathrm{mM}(\mathrm{A}) \mathbf{L} 1$ and (B) $\mathbf{L} 2$ with incremental addition of $\mathrm{Fe}^{3+}$ ion in methanol containing $0.1 \mathrm{M} \mathrm{TBAP}$ at a scan rate of $50 \mathrm{mV} \mathrm{s}^{-1}$.

for $\mathbf{L 1 / L 2}$ are due to the oxidation of tert-butyl-substituted phenolic hydroxyl groups to phenoxyl radical $\left(\mathrm{PhO}^{\bullet}\right) .{ }^{30}$ The second peak at $1.01 \mathrm{~V}$ corresponds to the oxidation of the unsubstituted phenolic hydroxyl group of $\mathbf{L 1}$, and that at $1.15 \mathrm{~V}$ corresponds to the oxidation of the methyl-substituted phenolic hydroxyl group. Upon successive addition of 50 to $200 \mu \mathrm{M} \mathrm{Fe}{ }^{3+}$ ions, the peak currents for both the oxidation peaks decreased gradually with slight positive shifts in their potentials, and a new signal appeared. The new peaks appeared at 0.89 and $1.23 \mathrm{~V}$ for $\mathbf{L 1}$ and at 0.91 and $1.28 \mathrm{~V}$ for $\mathbf{L} 2$. The positive shifts in the oxidation potentials in the presence of $\mathrm{Fe}^{3+}$ ions clearly indicate that both the hydroxyl groups of the ligands are coordinated to the metal ion. These observations further substantiate the binding mechanisms proposed in the previous sections and provide a new avenue for developing electrochemical sensors for the detection of $\mathrm{Fe}^{3+}$ using these newly developed Schiff base compounds.

\section{Conclusions}

In this work, we have synthesized simple Schiff base AIE-active ligands $\mathbf{L 1}$ and $\mathbf{L} 2$ and developed these ligands as efficient naked eye probes and fluorescent turn-off sensors for the selective 
detection of $\mathrm{Fe}^{3+}$ ions in $\mathrm{THF}-\mathrm{H}_{2} \mathrm{O}$ medium. A noticeable colour change could be visually observed for $\mathbf{L 1}$ and $\mathbf{L} 2$ in the presence of $\mathrm{Fe}^{3+}$ ion. As fluorescent sensors, both the ligands were highly selective towards $\mathrm{Fe}^{3+}$ among other coexisting metal ions with a 1:1 binding ratio, and the detection limits were found to be $0.163 \mu \mathrm{M}$ and $3.99 \mu \mathrm{M}$ for $\mathbf{L} 1$ and $\mathbf{L} 2$, respectively. The fluorescence turn-off responses of $\mathbf{L} 1$ and $\mathbf{L} 2$ to $\mathrm{Fe}^{3+}$ can be attributed to a PET inhibition mechanism, as was demonstrated using DFT calculations and lifetime measurements. The association constants $\left(K_{\mathrm{a}}\right)$ of $\mathbf{L} \mathbf{1}$ and $\mathbf{L} 2$ in the presence of $\mathrm{Fe}^{3+}$ were calculated to be $1.317 \times 10^{5} \mathrm{M}^{-1}$ and $2.930 \times 10^{5} \mathrm{M}^{-1}$, respectively. The quantum yields of both ligands are higher than those of their $\mathrm{Fe}^{3+}$ complexes, which is indicative of fluorescence quenching by $\mathrm{Fe}^{3+}$ ion. The binding of ligands with $\mathrm{Fe}^{3+}$ was also ascertained by electrochemical investigations. Due to the low detection limits and the strong and selective binding attained with the newly developed AIE-active fluorophores, they are expedient for the detection of $\mathrm{Fe}^{3+}$ ions in complex environmental and biological samples.

\section{Conflicts of interest}

There are no conflicts to declare.

\section{Acknowledgements}

The authors thank the Vellore Institute of Technology (VIT) for providing a VIT SEED GRANT for carrying out this research work and are also thankful to DST-SIF, VIT for providing NMR, IR, GC-MS and other analytical facilities.

\section{References}

1 (a) J. L. Bricks, A. Kovalchuk, C. Trieflinger, M. Nofz, M. Buschel, A. L. Tolmachev, J. Daub and K. Rurack, On the development of sensor molecules that display $\mathrm{Fe}^{\mathrm{III}}$-amplified fluorescence, J. Am. Chem. Soc., 2005, 127(39), 13522-13529; (b) S. Wang, X. Meng and $\mathrm{M}$. Zhu, A naked-eye rhodamine-based fluorescent probe for Fe(III) and its application in living cells, Tetrahedron Lett., 2011, 52(22), 2840-2843.

2 (a) D. Galaris, V. Skiada and A. Barbouti, Redox signaling and cancer: the role of "labile" iron, Cancer Lett., 2008, 266(1), 21-29; (b) H. Kozlowski, A. Janicka-Klos, J. Brasun, E. Gaggelli, D. Valensin and G. Valensin, Copper, iron, and zinc ions homeostasis and their role in neurodegenerative disorders (metal uptake, transport, distribution and regulation), Coord. Chem. Rev., 2009, 253(21-22), 2665-2685; (c) S. Sen, S. Sarkar, B. Chattopadhyay, A. Moirangthem, A. Basu, K. Dhara and P. Chattopadhyay, A ratiometric fluorescent chemosensor for iron: discrimination of $\mathrm{Fe}^{2+}$ and $\mathrm{Fe}^{3+}$ and living cell application, Analyst, 2012, 137(14), 3335-3342.

3 (a) M. E. Del Castillo Busto, M. Montes-Bayon, E. BlancoGonzalez, J. Meija and A. Sanz-Medel, Strategies to study human serum transferrin isoforms using integrated liquid chromatography ICPMS, MALDI-TOF and ESI-Q-TOF detection: application to chronic alcohol abuse, Anal. Chem., 2005, 77(17),
5615-5621; (b) S. R. Liu and S. P. Wu, New water-soluble highly selective fluorescent chemosensor for $\mathrm{Fe}(\mathrm{III})$ ions and its application to living cell imaging, Sens. Actuators, B, 2012, 171, 1110-1116; (c) M. G. Van Den Berg, Chemical speciation of iron in seawater by cathodic stripping voltammetry with dihydroxynaphthalene, Anal. Chem., 2006, 78(1), 156-163; (d) S. Lunvongsa, M. Oshima and S. Motomizu, Determination of total and dissolved amount of iron in water samples using catalytic spectrophotometric flow injection analysis, Talanta, 2006, 68(3), 969-973.

4 D. Wei, Y. Sun, J. Yin, G. Wei and Y. Du, Design and application of $\mathrm{Fe}^{3+}$ probe for "naked-eye" colorimetric detection in fully aqueous system, Sens. Actuators, B, 2011, 160(1), 1316-1321.

5 (a) A. P. D. Silva, H. Q. N. Gunaratne, T. Gunnlaugsson, A. J. M. Huxley, C. P. McCoy, J. T. Rademacher and T. E. Rice, Signaling recognition events with fluorescent sensors and switches, Chem. Rev., 1997, 97(5), 1515-1566; (b) K. Velmurugan, J. Prabhu, A. Raman, N. Duraipandy, M. S. Kiran, S. Easwaramoorthi, L. Tang and R. Nandhakumar, Dual functional fluorescent chemosensor for discriminative detection of $\mathrm{Ni}^{2+}$ and $\mathrm{Al}^{3+}$ ions and its imaging in living cells, ACS Sustainable Chem. Eng., 2018, 6(12), 16532-16543; (c) P. C. A. Swamy and P. Thilagar, Triarylborane-Appended new triad and tetrad: chromogenic and fluorogenic anion recognition, Inorg. Chem., 2014, 53(6), 2776-2786; (d) N. Murugan and A. K. Sundramoorthy, Green synthesis of fluorescent carbon dots from Borassus flabellifer flowers for label-free highly selective and sensitive detection of $\mathrm{Fe}^{3+}$ ions, New J. Chem., 2018, 42(16), 13297-13307.

6 (a) G. G. Huang, Y. T. Chen and Y. R. Lin, Development of a gold nanoparticle based anti-aggregation method for rapid detection of mercury(II) in aqueous solutions, Anal. Methods, 2014, 6(15), 5690-5696; (b) S. K. Sahoo, D. Sharma, R. K. Bera, G. Crisponi and J. F. Callan, Iron(III) selective molecular and supramolecular fluorescent probes, Chem. Soc. Rev., 2012, 41(21), 7195-7227; (c) B. Valeur and I. Leray, Design principles of fluorescent molecular sensors for cation recognition, Coord. Chem. Rev., 2000, 205(1), 3-40; (d) M. Zulfajri, G. Gedda, C. J. Chang, Y. P. Chang and G. G. Huang, Cranberry beans derived carbon dots as a potential fluorescence sensor for selective detection of $\mathrm{Fe}^{3+}$ ions in aqueous solution, ACS Omega, 2019, 4(13), 15382-15392.

7 (a) W. J. Ansorge, Next-generation DNA sequencing techniques, New Biotechnol., 2009, 25(4), 195-203; (b) K. P. Carter, A. M. Young and A. E. Palmer, Fluorescent sensors for measuring metal ions in living systems, Chem. Rev., 2014, 114(8), 4564-4601.

8 (a) Y. Hong, J. W. Y. Lam and B. Z. Tang, Aggregationinduced emission, Chem. Soc. Rev., 2011, 40(11), 5361-5388; (b) Z. Zhao, J. W. Y. Lam and B. Z. Tang, Aggregationinduced emission of tetraarylethene luminogens, Curr. Org. Chem., 2010, 14(18), 2109-2132.

9 (a) W. L. Gong, M. P. Aldred, G. F. Zhang, C. Li and M. Q. Zhu, Aggregation-induced emission logic gates based on metal ion sensing of phenanthroline-tetraphenylethene conjugates, 
J. Mater. Chem. C, 2013, 1(45), 7519-7525; (b) Q. Li, X. Wu, X. Huang, Y. Deng, N. Chen, D. Jiang, L. Zhao, Z. Lin and Y. Zhao, Tailoring the fluorescence of AIE active metalorganic frameworks for aqueous sensing of metal ions, ACS Appl. Mater. Interfaces, 2018, 10(4), 3801-3809; (c) M. Gao and B. Z. Tang, Fluorescent sensors based on aggregation-induced emission: recent advances and perspectives, ACS Sens., 2017, 2(10), 1382-1399; (d) J. Tavakoli, S. Pye, A. H. M. M. Reza, N. Xie, J. Qin, C. L. Raston, B. Z. Tang and Y. Tang, Tuning aggregation-induced emission nanoparticle properties under thin film formation, Mater. Chem. Front., 2020, 4, 537-545.

10 (a) Y. Yoon, S. Jo, S. J. Park, H. M. Kim, D. Kim and T. S. Lee, Unusual fluorescence of o-phenylazonaphthol derivatives with aggregation-induced emission and their use in twophoton cell imaging, Chem. Commun., 2019, 55(47), 6747-6750; (b) S. Mukherjee and P. Thilagar, Insights into the AIEE of 1,8Naphthalimides (NPIs): inverse effects of intermolecular interactions in solution and aggregates, Chem. - Eur. J., 2014, 20(26), 8012-8023.

11 J. Mei, N. L. C. Leung, R. T. K. Kwok, J. W. Y. Lam and B. Z. Tang, Aggregation-induced emission: together we shine, united we soar!, Chem. Soc. Rev., 2015, 115(21), 11718-11940.

12 (a) Y. Chen, W. Zhang, Y. Cai, R. T. Kwok, Y. Hu, J. W. Y. Lam, X. Gu, Z. He, Z. Zhao, X. Zheng, B. Chen, C. Gui and B. Z. Tang, AIEgens for dark through-bond energy transfer: design, synthesis, theoretical study and application in ratiometric $\mathrm{Hg}^{2+}$ sensing, Chem. Sci., 2017, 8(3), 2047-2055; (b) M. Shellaiah, Y. H. Wu, A. Singh, M. V. R. Raju and H. C. Lin, Novel pyrene- and anthracene-based Schiff base derivatives as $\mathrm{Cu}^{2+}$ and $\mathrm{Fe}^{3+}$ fluorescence turn-on sensors and for aggregation induced emissions, J. Mater. Chem. A, 2013, 1(4), 1310-1318; (c) Z. Song, T. K. K. Ryan, D. Ding, H. Nie, J. W. Y. Lam, B. Liu and B. Z. Tang, An AIE-active fluorescence turn-on bioprobe mediated by hydrogenbonding interaction for highly sensitive detection of hydrogen peroxide and glucose, Chem. Commun., 2016, 52(65), 10076-10079; (d) R. T. Kwok, C. W. Leung, J. W. Y. Lam and B. Z. Tang, Biosensing by luminogens with aggregation induced emission characteristics, Chem. Soc. Rev., 2015, 44(13), 4228-4238.

13 (a) Y. He, Y. Li, H. Su, Y. Si, Y. Liu, Q. Peng, J. He, H. Hou and $\mathrm{K}$. Li, An $o$-phthalimide-based multistimuli-responsive aggregation-induced emission (AIE) system, Mater. Chem. Front., 2019, 3(1), 50-56; (b) S. K. Padhan, N. Murmu, S. Mahapatra, M. K. Dalai and S. N. Sahu, Ultrasensitive detection of aqueous $\mathrm{Cu}^{2+}$ ions by a coumarin-salicylidene based AIEgen, Mater. Chem. Front., 2019, 3(11), 2437-2447; (c) J. Prabhu, K. Velmurugan, A. Raman, N. Duraipandy, M. S. Kiran, S. Easwaramoorthi and R. Nandhakumar, A simple chalcone based ratiometric chemosensor for sensitive and selective detection of nickel ion and its imaging in live cells, Sens. Actuators, B, 2017, 238, 306-317; (d) B. Fan, J. Wei, X. Ma, X. Bu, N. Xing, Y. Pan, L. Zheng and W. Guan, Synthesis of lanthanide-based room temperature ionic liquids with strong luminescence and selective sensing of $\mathrm{Fe}(\mathrm{III})$ over mixed metal ions, Ind. Eng. Chem. Res., 2016, 55(7), 2267-2271.
14 (a) T. Han, Y. Hong, N. Xie, S. Chen, N. Zhao, E. Zhao, J. W. Y. Lam, H. H. Sung, Y. Dong, B. Tong and B. Z. Tang, Defectsensitive crystals based on diaminomaleonitrile functionalized Schiff base with aggregation-enhanced emission, J. Mater. Chem. C, 2013, 1(44), 7314-7320; (b) W. Tang, Y. Xiang and A. Tong, Salicylaldehyde azines as fluorophores of aggregation induced emission enhancement characteristics, J. Org. Chem., 2009, 74(5), 2163-2166; (c) M. Ziolek, M. Gil, J. A. Organero and A. Douhal, What is the difference between the dynamics of anion- and keto-type of photochromic salicylaldehyde azine?, Phys. Chem. Chem. Phys., 2010, 12(9), 2107-2115.

15 (a) N. Zhao, Y. H. Wu, J. Luo, L. X. Shi and Z. N. Chen, Aggregation-induced phosphorescence of iridium(III) complexes with 2,2'-bipyridine-acylhydrazone and their highly selective recognition to $\mathrm{Cu}^{2+}$, Analyst, 2013, 138(3), 894-900; (b) Y. Q. Sun, P. Wang, J. Liu, J. Zhang and W. Guo, A fluorescent turn-on probe for bisulfite based on hydrogen bond-inhibited $\mathrm{C}=\mathrm{N}$ isomerization mechanism, Analyst, 2012, 137(15), 3430-3433.

16 W. G. Jia, H. Zhang, T. Zhang, D. Xie, S. Ling and E. H. Sheng, Half-Sandwich ruthenium complexes with Schiff-Base ligands: syntheses, characterization, and catalytic activities for the reduction of nitroarenes, Organometallics, 2016, 35(4), 503-512.

17 (a) R. Kagit, M. Yildirim, O. Ozay, S. Yesilot and H. Ozay, Phosphazene based multicentered naked eye fluorescent sensor with high selectivity for $\mathrm{Fe}^{3+}$ ions, Inorg. Chem., 2014, 53(4), 2144-2151; (b) O. Sadak, A. K. Sundramoorthy and S. Gunasekaran, Highly selective colorimetric and electrochemical sensing of iron(III) using Nilered functionalized graphene film, Biosens. Bioelectron., 2017, 89, 430-436.

18 D. Roy, A. Chakraborty and R. Ghosh, Perimidine based selective colorimetric and fluorescent turn-off chemosensor of aqueous $\mathrm{Cu}^{2+}$ : studies on its antioxidant property along with its interaction with calf thymus-DNA, RSC Adv., 2017, 7(64), 40563-40570.

19 S. Densil, C. H. Chang, C. L. Chen, A. Mathavan, A. Ramdass, V. Sathish, P. Thanasekaran, W. S. Li and S. Rajagopal, Aggregation-induced emission enhancement of anthracene derived Schiff base compounds and their application as a sensor for bovine serum albumin and optical cell imaging, Luminescence, 2018, 33(4), 780-789.

20 K. Boonkitpatarakul, J. Wang, N. Niamnont, B. Liu, L. Mcdonald, Y. Pang and M. Sukwattanasinitt, Novel turn-on fluorescent sensors with mega Stokes shifts for dual detection of $\mathrm{Al}^{3+}$ and $\mathrm{Zn}^{2+}$, ACS Sens., 2016, 1(2), 144-150.

21 X. G. Li, Y. Liao, M. R. Huang, V. Strong and R. B. Kaner, Ultra-sensitive chemosensors for $\mathrm{Fe}(\mathrm{III})$ and explosives based on highly fluorescent oligofluoranthene, Chem. Sci., 2013, 4(5), 1970-1978.

22 D. Yang, C. Dai, Y. Hu, S. Liu, L. Weng, Z. Luo, Y. Cheng and L. Wang, A new polymer-based fluorescent chemosensor incorporating propane-1,3-dione and 2,5-diethynylbenzene moieties for detection of copper(II) and iron(III), Polymers, 2017, 9(7), 267.

23 P. Maity, B. Naskar, S. Goswami, C. Prodhan, T. Chaudhuri, K. Chaudhuri and C. Mukhopadhyay, Pyrrolo[3,4-c]pyridinebased fluorescent chemosensor for $\mathrm{Fe}^{3+} / \mathrm{Fe}^{2+}$ sensitivity and 
their application in living HepG2 cells, ACS Omega, 2018, 3(12), 18646-18655.

24 B. Sui, S. Tang, T. Liu, B. Kim and K. D. Belfield, Novel BODIPY based fluorescence turn-on sensor for $\mathrm{Fe}^{3+}$ and its bioimaging application in living cells, ACS Appl. Mater. Interfaces, 2014, 6(21), 18408-18412.

25 C. Wang, J. Fu, K. Yao, K. Xue, K. Xu and X. Pang, Acridinebased fluorescence chemosensors for selective sensing of $\mathrm{Fe}^{3+}$ and $\mathrm{Ni}^{2+}$ ions, Spectrochim. Acta, Part A, 2018, 199, 403-411.

26 B. Zhang, H. Liu, F. Wu, G. Hao, Y. Chen, C. Tan, Y. Tan and Y. Jiang, A dual-response quinoline-based fluorescent sensor for the detection of copper(II) and iron(III) ions in aqueous medium, Sens. Actuators, B, 2017, 243, 765-774.

27 G. Y. Gao, W. J. Qu, B. B. Shi, P. Zhang, Q. Lin, H. Yao, W. L. Yang, Y. M. Zhang and T. B. Wei, A highly selective fluorescent chemosensor for iron ion based on $1 \mathrm{H}$-imidazo[4,5- $b]$ phenazine derivative, Spectrochim. Acta, Part A, 2014, 121, 514-519.

28 M. Oguz, A. N. Kursunlu and M. Yilmaz, Low-cost and environmentally sensitive fluorescent cellulose paper for naked-eye detection of Fe(III) in aqueous media, Dyes Pigm., 2020, 173, 107974.

29 H. X. Yu, J. Zhi, Z. F. Chang, T. Shen, W. L. Ding, X. Zhang and J. L. Wang, Rational design of aggregation-induced emission sensor based on rhodamine B for turn-on sensing of trivalent metal cations, reversible data protection, and bioimaging, Mater. Chem. Front., 2019, 3(1), 151-160.

30 D. Tomczyk, W. Bukowski and K. Bester, Redox processes in the solution of $\mathrm{Ni}(\mathrm{II})$ complex with salen type ligand and in the polymer films, Electrochim. Acta, 2018, 267, 181-194. 